\title{
Light intensity measurement and the biting behaviour of some sylvatic moqsuitoes of the Amazon basin (Diptera: Culicidae)
}

\author{
J. Derek Charlwood (') \\ José Lopes $\left({ }^{2}\right)$ \\ Peter C. Whalley $\left({ }^{3}\right)$
}

\begin{abstract}
The design of a lightmeter suitable for use at low light levels is described. Catches of mosquitoes biting man at sunset near Manaus Amazonas indicated that light intensity controls biting activity in crepuscular species to a very fine degree.
\end{abstract}

\section{INTRODUCTION}

It is well known that the flight periodicities of many species of mosquito is governed by an endogenous 'circadian clock' (Jones et al., 1967, 1974; Nayar \& Sauerman, 1971; Saunders, 1976). Activity in such species may be affected by the changing light intensities at sunset. The difficulties associated with measuring the very low light intensities prevailing at these times mean that, in general, the degree of control of behaviour by light intensity is unknown.

This paper describes a very simple light meter suitable for use at low light intensities and gives the rasults of a preliminary investigation of the biting behaviour of some Amazonian mosquitoes at sunset.

\section{METHODS}

\section{LIGHT MEASUREMENTS}

Accurate measurement of low levels of illumination has formeriy required complicated electronic equipment (Davies, 1975; Callahan, 1964; Lumsden, 1966). The expanding research in electronics has led to the development of more efficient phototransistors than have previously been available. Accordingly an instrument, suitable for the measurement of light levels below 0.1 Lux, was designed and constructed using a photodarlington transistor as the light sensitive element. Incident light was detected by a 2 N577 (G.E.) transistor mounted in a diecast aluminium box. The output from this was monitored by a digital, battery operatec, voltmeter. Twelve $1.5 \mathrm{~V}$ battries, stepped down by a $15 \mathrm{~V}$ regulator, supplied the power to the transistor. This ensured that the supply to the transistor remained constant during the time when the batteries began to run down. In practise the meter uses very little current so that the life of one set of batteries is effectively equivalent to their shelf life. No suitable light source was available to standardize the meter. Approximate comparisons were made with a 'Metrawatt Lux meter, the most sensitive light meter that could be obtained. This gave consistent results down to 2.5 Lux. The calibration curve of the phototransistor down to this is shown in figure I. There was a good correlation between volts and Lux $(r=0.960, P=70.001)$. Output belov 1.0 Lux was checked using the principle of the inverse square law of light transmission (ie. iight intensity drops decreases by a square root as the distance from the source doubles) with a standard light source. Since the output of the transistor is effectively linear with light intensity it is possible to light readings from the digital voltmeter to values of 0.1 Lux. Vaiues below 0.005 volts were considered to equate to zero as this level approached the limits of accuracy of the voltmeter.

(1) - Sunnybank Farm, Bolsterstone, Sheffield S305ZL. Inglaterra.

(2) - Instituto Nacional de Pesquisas da Amazônia, Manaus.

(3) - I.E.T., Open University, Milton Keynes, Bucks, Inglaterra. 


\section{BITING CATCHES}

Using the lightmeter the biting behaviour of mosquitoes in secondary forest near the city of Manaus was studied at sunset. Mosquitoes were collected as they came to feed on the exposed iower legs of human bait at the campus of the University of Amazonas. After synchronizing watches one collector stationed himself approximately $30 \mathrm{~m}$ inside the forest and another collector remained in the open ten metres from the forest edge. Insects were caught in numbered test tubes as they started to probe and the time that they were caught was noted. On alternate days the collectors changed places.

For light measurements the lightmeter was placed on the ground with the light sensitive element facing the sky. Readings were taken at the start of every minute. A digital watch was used to monitor the time. Light measurements were taken inside and outside of the forest on alternate days. Temperature and humidity were measured using a wet and dry bulb thermometer. Catches were made on ten moonless occasions in Cctober 1978 and on three occasions in May 1979.

\section{RESULTS}

In all collections the temperature was $25 \pm 2{ }^{\circ} \mathrm{C}$ and the relative humidity was $75-90 \%$.

The predominante species collected was Culex coronator D.\&K. This species comprised

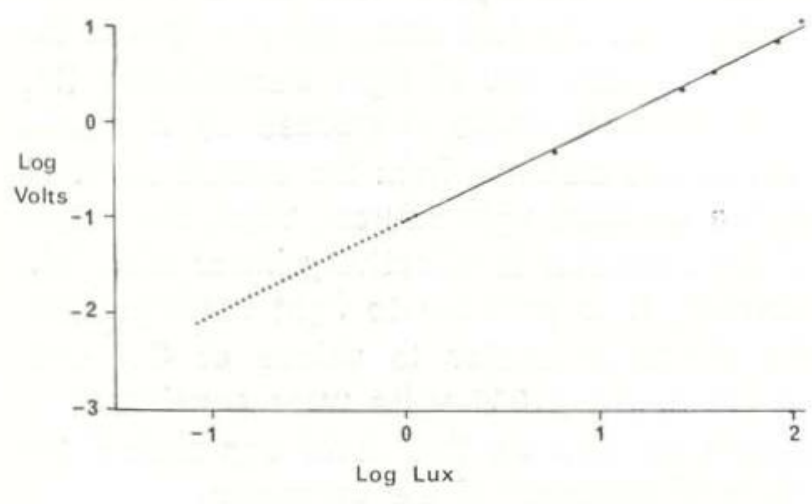

Fig. 1 - Calibration curve of the lightmeter derived with a Metrawatt Luxmeter. The dotted line gives the estimated Lux value obtained from a standard light source and the inverse square law.

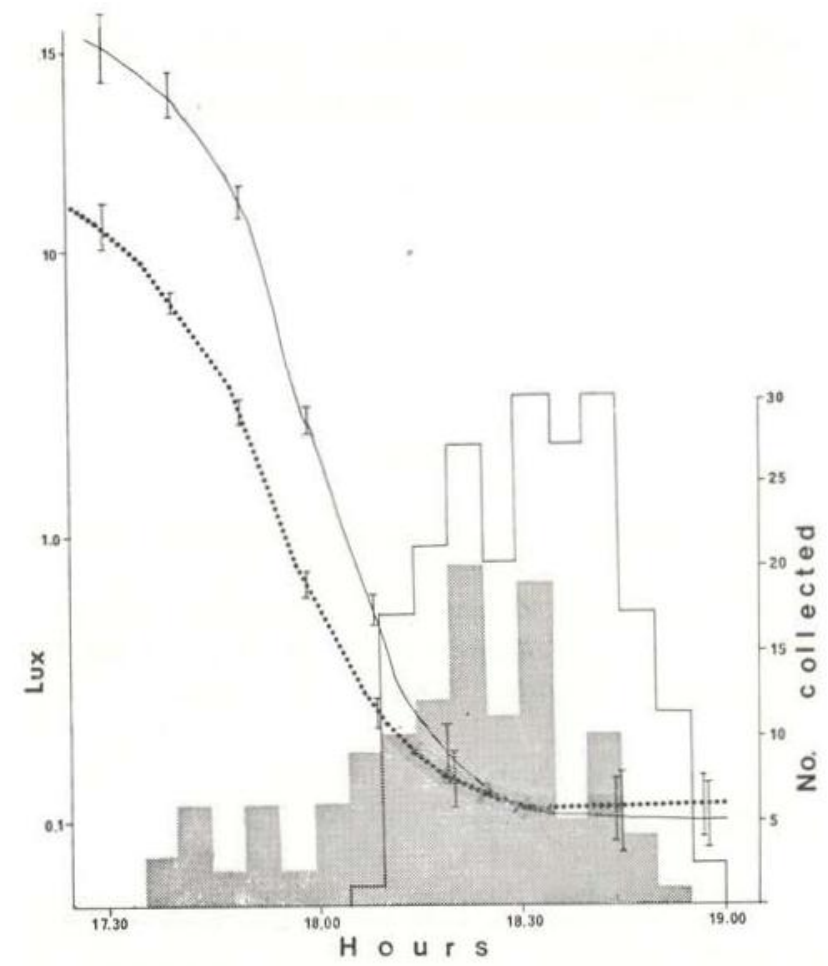

Fig. 2 - Light intensity and numbers of mosquito biting man at the dge of and inside secondary forest near the city of Manaus. Numbers collected inside the forest. $\cdots$. Light intensity inside the forest. Bars indicate range of values from the ten colletctions.

approximately $75 \%$ of all insects caught biting inside and outside the forest. Mansonia amazonensis (Theo) and M.titillans (WIk) together made up the bulk of the remainder of the insects caught. Small numbers of Psorophora albipes (Theo), P. ferox (Humboltd) Anopheles mediopunctatus (Theo) A. oswoldoi Peryassu and three species of unidentified Culex were also collected. The total number of mosquitoes collected inside and sutside the forest at sunset is shown in Figure 2 with the mean light intensity obtained at these times. The peak of biting occurs approximately ten minutes earlier inside the forest than outside. This is related to the drop in light intensity which also occurs ten minutes earlier inside the forest.

A similar relationship between light intensity and biting activity of $C$. coronator collested on succesive days in the forest. The change in light level was five minutes earlier on the first day than on the succeding day. Figure 3 and $3 a$ demonstrate that the peak of 
biting also differed by five minutes in the two days. Peak biting occured at approximately 0.1 Lux on both days.

\section{DISCUSSION}

Flight activity of Culex quinquefasciatus Say, in the laboratory, is initiated at a set light intensity irrespective of the speed of artificial 'dusk' to which the insects are subjected (Charlwood, 1976). Swarms of mosquito also appear to be inaugurated at particular threshold light intensities (Corbet, 1964). The results of biting catches reported here also indicate that light intensity, rather than time, acts as a cue for initiating activity in some

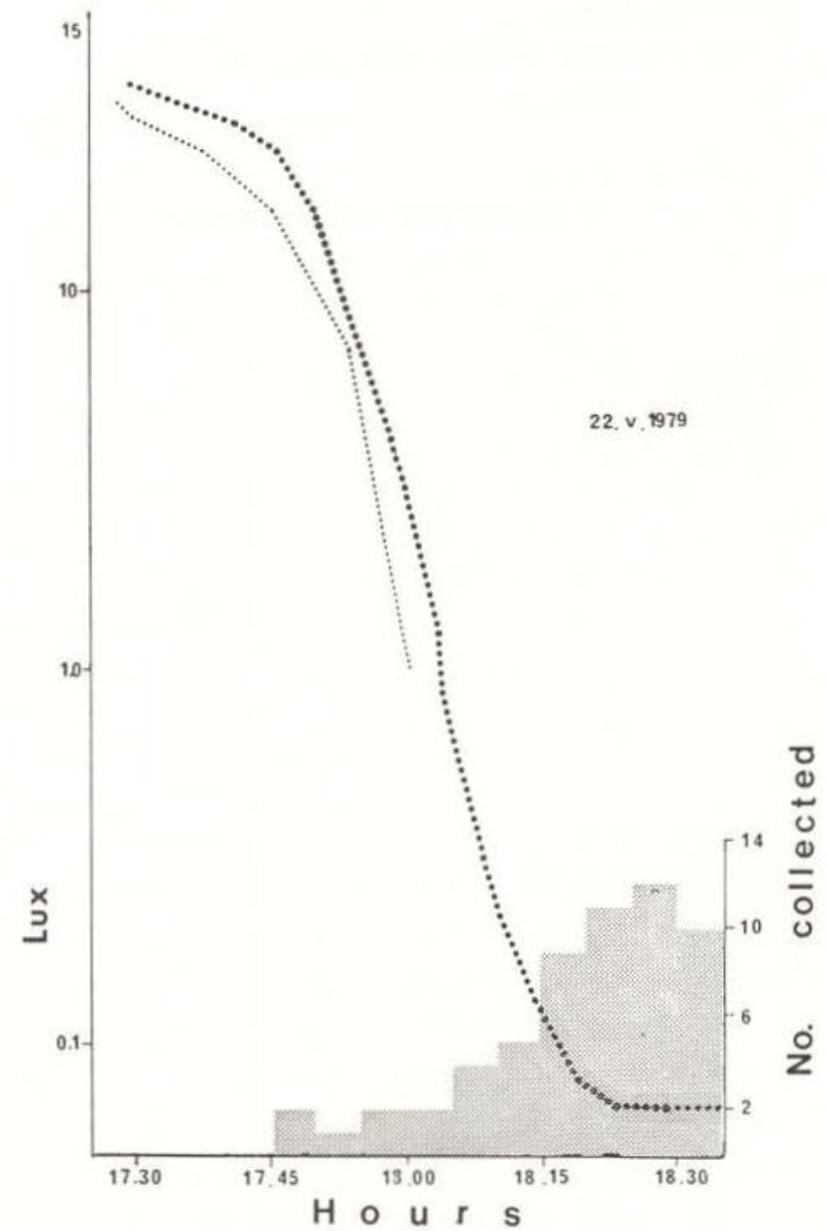

species of Neotropical mosquito. Undoubtedly the response to these cues is under the overall control of the circadian clock.

The fact that peak biting activity took place at levels of illumination below that of full moonlight (calculated as 0.21 Lux, Bidling. mayer, 1964) means that lunar phase is likely to affect biting behaviour in these species. This aspect of their behaviour remains to be investigated.

\section{ACKNOWLEDGEMENTS}

We wish to acknowledge the following persons for their assistance in the field: A.M. Soares and A.V.P. Napoles.

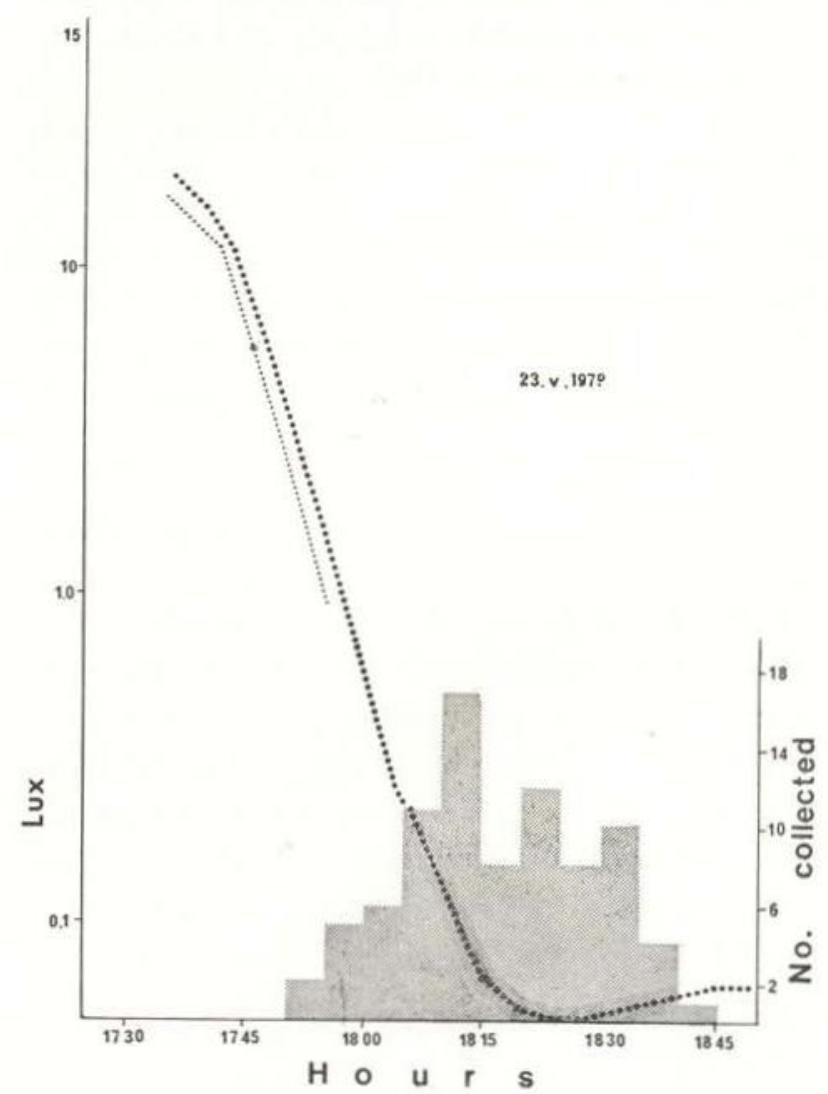

Flg. 3 - Light intensity and number of Culex coronator collected biting man in secondary forest near the city of Manaus on two succesive days: .. Light intensity derived from the "Metrawatt" Luxmeter; Light intensity derived from the lightmeter described. 


\section{RESUMO}

E descrito um luximetro apropriado para uso em baixo nivel de luz. Mosquitos picando o homem capturados ao entardecer, em uma área próxima a Manaus, Amazonas, indicaram que a intensidade de luz controla a atividade de picada em um grau muito sensível, nas espécies crepusculares.

\section{REFERENCES}

BIDLINGMAYER, W.L.

1964 - The effect of monlight on the flight activity of mosquitoes. Ecology, 45: 87-94.

CALLAHAN, P.S.

1964 - An inexpensive actinometer for continuous field recording of moonlight, daylight or lowintensity evening light. J. econ. Ent., 57: 758-760.

CHARLWOOD, J.D.

1976 - The mating behaviour of mosquitoes. Ph.D. thesis. University of Sussex.

CORBET, P.S.

1964 - Observations on the swarming and mating of mosquitoes in Uganda. Proc. R. ent. Soc. Lond. (A), 39: 15-22.
DAVIES, J.B.

1975 - Moonligth and the biting activity of Culex (Melanoconion) portesi Senevet \& Abonnenc and C. (M.) taeniopus D. \& $\mathrm{K}$. in Trinidad forests. Bull. ent. Res., 65: 81-96.

JONES, M.D.R.; HILL, M.; HOPE, A.M.

1967 - The circadian flight activity of the mosquito Anopheles gambiae: phase setting by the light regime. J. exp. Biol., 47: 503-511.

JONES, M.D.R.; GUBBINS, S.J.; CUBBIN, C.M.

1974 - Circadian flight activity in four sibling species of the Anopheles gambiae complex (Diptera, Culicidae). Bull. ent. Res., 64: 241246.

NAYAR, J.K. \& SAUERMAN, D.M. Jr.

1971 - The effect of light regimes on the circadian rhythm of flight activity in the mosquito Aedes taeniorhynchus. J. exp. Biol., 54: 745-756.

SAUNDERS, D.S.

1976 - Insect Clocks. New York, Pergamon Press. $279 p$.

(Aceito para publicação em 10/06/80) 